\title{
The Impact of Internal Control and Risk Management on Banks in Palestine
}

\author{
Mohammed Bayyoud*, Nermeen Ahmad Sayyad \\ Faculty of Business \& Economics, Al-Quds University, Jerusalem, Palestine \\ Email address: \\ mbayyoud@admin.alquds.edu (M. Bayyoud),nermeen@admin.alquds.edu (N. Nermeen)
}

\section{To cite this article:}

Mohammed Bayyoud, Nermeen Ahmad Sayyad. The Impact of Internal Control and Risk Management on Banks in Palestine. International Journal of Economics, Finance and Management Sciences. Vol. 3, No. 3, 2015, pp. 156-161.doi: 10.11648/j.ijefm.20150303.12

\begin{abstract}
The purpose of the study attempts to analyze the impact of internal control and risk management on banks in Palestine. The investigation helped in identifying the impacts of new banking reformations and rules on the risk assessment, identification, and mitigation in banks. It was also assessed that whether frauds and errors are reduced, different types of risk are controlled, duties are segregated and practices are aligned with international standards in banks due to reformed internal control procedures. A qualitative close-ended survey was carried out for collecting data from managers of 10 banks in Palestine. The responses of 22 statements were collected in five different categories. The findings showed that overall internal control and risk management systems in Palestine have positively affected the banks in terms of quantitative as well as qualitative performance.
\end{abstract}

Keywords: Internal Control, Risk Management, Risk Assessment, Risk Identification, Palestinian Banks

\section{Introduction}

Due to recent financial scandals and economic crisis, banking sector all across the globe has become vulnerable to the fraudulent actions. Rising uncertainties and development of more instruments have pressurized the banking organizations to look for the appropriate internal measures to transform their business organization as risk and uncertainty proof. Internal control and risk management are identified as two crucial aspects. In contemporary globalised market, banking management is required to have working knowledge of the risk management instruments in order to mitigate the level of risk (Abdelkarim and Burbar).

Similarly, banking sector in Palestine has increased their hardships due to the uncertain institutional and political environments. It can be analyzed that after the state has signed the Paris Protocol (PP) in the year 1994, NIS, JD, and US dollar have replaced the Palestine's national currency, ultimately improving the burden of risk management for banking institutions. On the other hand, continuously changing international banking sector in contexts of deregulated environment, rapid advances in information and communications technology, and steady modernization in financial technology are also challenging issues pressurizing the need of internal control and risk management in Palestine.
The pressures from internal and international conditions in the financial industry have increased the responsibility of the new reforms and rules for banking internal control and risk management systems. Therefore, the study attempts to analyze the impact of internal control and risk management on banks in Palestine. These impacts would be traced in terms of resolving numerous sector challenges like reducing uncertainty. The investigation will further help in evaluating the performances of both the systems supervised by the new banking laws and reforms in Palestine banks to substantiate whether or not these are working according to the international banking standards.

\section{Literature Review}

A wide range of academic literature can be found discussing the meaning, reasons and types of strategies adopted by the banks at international level in order to control or supervise their internal systems and monitor variety of risks these institutions are exposed to.

\subsection{Internal Control in Banking Sector}

Banking Regulation and Supervision Board has defined 
internal control system as "all of the financial, operational and other control systems which are carried out by internal controllers and which involve monitoring, independent evaluation and timely reporting to management levels systematically in order to ensure that all the bank activities are performed by management levels in accordance with current policies, methods, instructions and limits (2)"

The definition elaborates the concept from a broader coverage and examined the vital role played by the independent internal control in identifying and assessing that practices are aligned with the industry policies. Bahu, Melloul and Walsh in their literature have also identified the importance of independency in internal control as the key aspect. They argued that without independency, the internal controls cannot be deemed as efficient and successful. An independent controller is therefore required to look after the actions of management and the overall operations of the business organization.

\subsubsection{Reason for Internal Control}

In the past studies, the key reason behind adopting the internal control systems within the banking sector can be identified as the need to assess continually that bank objectives are being recognized. In a research conducted to analyze the importance of internal control for the Nigerian banks, Hayali, Dinç and Sarılı reported that internal controls help the financial sector in presenting its strong and stable outlook in front of the international spectators. It helps in monitoring the assets and maintaining the reliability of the company's accounts and keeping a strict eye on fraudulent activities. Similarly, Socol has further added that the main objective behind banking internal control includes continuous tracking of activities with international auditing standards. This can help in solving any problem that may arise. An effective system is capable of detecting errors, fraudulent transactions as well as any irregularities and ultimately reduces the percentage of such occurrences.

\subsubsection{Types of Internal Control}

General literature has also discussed the different types of internal control used within the banking sector. According to D. P. Dube, there are three types of internal controls used in banking sector based on the automated or information technology environment adopted by the management. These include;

- Preventive internal controls

- Corrective internal controls

- Detective internal controls

Likewise, the Risk Management Committee emphasized on Basle Committee of Banking Supervision issues a framework for documentation by focusing on six major head; a bank can develop a strong and efficient internal control. These included;

- "Management oversight and the board control culture

- Risk recognition and assessment

- Control activities and segregation of duties

- Information and communications

- Monitoring activities and correcting deficiencies
- Evaluation of internal control systems by supervising authorities (D. P. Dube 58-61)

It can be analyzed from the above literature analysis that risk controlling and management is the key function of the internal control system. Therefore, the next section discusses distinctly the risk management in banking sector.

\subsection{Risk Management in Banking Sector}

According to Banking Regulation and Supervision Board, risk management system is defined as,

"all of the mechanisms concerning the process of standardsetting, reporting, verifying the compliance with standards, decision-making and implementing, which are established by the board of directors in order to monitor, to keep under control and, if necessary, to change the risk/return structure of the future cash flows of the bank and, accordingly, the quality and the extend of the activities (2)" The definition highlights on the key function of risk management i.e. to control the risk or return structure of future cash flows. It can be analyzed that financial sector operates in the highly volatile market with foreign exchange fluctuations,

\subsubsection{Types of Risks}

Past studies and banking literature identify five major types of risks, which every bank has to confront. These include credit risk, market risk, liquidity risk, operational risk and compliance risk. Greuning and Bratanovic state that risk within the banking institutions is the consequence of the financial and non-financial decisions. Additionally, the other instances of risk may be the adoption and implementation of the operational and loan portfolio strategies. Since the banks are of different types and differ in activities, therefore consequentially the type, nature an amount of risk also varies among them. Managing these risks is based on the specific situation and condition.

\subsubsection{Strategies for Risk Management}

Greuning and Bratanovic report on the different types of strategies used for managing risk in the banks. These include risk monitoring and management of information systems, placement of appropriate internal controls, risk profiling, identifying and measuring specific risk, and development of policies for the mitigation of the risk (Greuning and Bratanovic). It is worth noting to examine that past studies have stressed on the management of credit risk more than other risks and prefer risk transfer as the most effective strategy for reducing the negative impacts of the risk on business operations (Arif and Anees; Sensarma and Jayadev).

The general theoretical overview of internal control and risk management in the banking sector will help in specifically focusing on the impacts of these two mechanisms on the overall performance of the Palestine banking sector after reformation. However, before conducting the primary research to achieve this key objective, the next section endeavors to highlight briefly the status of these two systems in Palestine. 


\section{Internal Control and Risk Management in Palestine}

\subsection{Brief Overview of Palestine Banking Sector}

Banking sector in Palestine is comprised of a central bank (Palestine Monetary Authority), approximately 11 national banks and 11 foreign banks operating with number of branches in different cities. The sector shows stability and sound performance after the implementation and regulation of monetary policies in Palestine after 1994 Paris Protocol (PPA; Cobham and Kanafani).

\subsection{Palestinian Banks and Application of Basel 2 Related to the Internal Control}

In order to assess the impact of internal control and risk management, understanding of the new requirements placed by Basel 2 are also required to be discussed. There are five key elements of this internal control framework; every bank in Palestine is required to follow.

1. First: The managerial supervision and control - The element is further based on three principles including responsibilities of the board, responsibilities of executive management and high standards of ethics and integrity.

2. Second: Risk identification and assessment

3. Third: Control activities and segregation of duties

4. Fourth: Information Systems and Communication

5. Fifth: Follow-up operations and corrections of imbalances (ibrabas)

The five key elements, on the other hand, refer to the key issues associated with internal control and risk assessment (ibrabas).

\section{Internal Control and Risk Management: Main Issue}

One of the critical issues associated with the internal control and risk management is that Palestine does not use its national currency in monitoring the banking sector transactions rather Israeli currency and USD dollars are used. The use of foreign currency increases the credit and market risks within the banking sector of Palestine (ibrabas; IBP USA). In an investigation report conducted by Abdelkarim and Burbar, authors have focused on the internal control and risk management systems of banks in Palestine, furthermore, the report focused also on how to manage financial risk. The report pointed out that banks in Palestine after reformation have shown good environment and control system. The findings indicate that at present, Palestinian banks have developed a set of internal control systems in order to identify risk arising from macro and micro environmental changes. These internal controls have helped the banks in the separation of duties by $45.5 \%$. These duties are divided between the risk analysts, risk controllers and mangers (Abdelkarim and Burbar).
Additionally, analysis shows that banks in Palestine normally develop a contingency plan for managing risks against disasters and accidents. In most of the banks, internal auditor is appointed to carry on with the risk management programs along with review, verification and validation of risk reports. Likewise, automatic back up and reliance on information and communication technologies is also evident within the Palestine banking sector (Abdelkarim and Burbar).

Additionally, due to the hostilities in Gaza and the deteriorating political and security environment, the PMA has currently given new instructions to the banks on stress testing in order to stay connected with the international risk management practices. The instructions include rules and minimum requirements on monitoring and follow-up potential of risks (PMA; Quigley; Silverburg; Valdivieso).

After examining Basel 2 requirements, the PMA initiatives and rules, major factors that can be summarized for further analysis in primary industry are listed below:

- Independency of internal control

- Segregation of duties

- Monitoring foreign currency fluctuations (Israeli currency and USA dollar)

- Financial risk indicates key risk in the sector

- Impact of broader economic and political environment on banking operations

- Dealing high uncertainty

- Alignment of banks' strategies with that of the Basel 2 and international requirements

\section{Methodology}

After reviewing the general as well as specific literature about the internal control and external in Palestine, a structured survey questionnaire was prepared and distributed to the managers and administrative level personnel in 10 banks. Online survey through mail was the research strategy. The findings gathered were purely qualitative in nature (Kapoulas and Mitic; Bryman and Bell). The response were gathered for 22 close-ended statements prepared around the key issues and the impact of current internal control and risk management strategies in Palestine in resolving all the issues. Likert-scale was used for reporting the responses. Survey strategy was found useful for the present investigation to collect large amount of data within the limited timeframe. The entire data collection procedure was based on 10 days procedure. Graphical representation of the findings was given for clarifying the results effectively (Karyn L. Neuhauser).

In this survey, impacts were measured around five elements of Basel 2 framework.

- The managerial supervision and control

- Risk identification and assessment

- Control activities and segregation of duties

- Information Systems and Communication

- Follow-up operations and corrections of imbalances 


\section{Survey Analysis}

The results of survey are given below. Frequency responses for agreement and standard deviation in the responses were measured for each 22 statements.

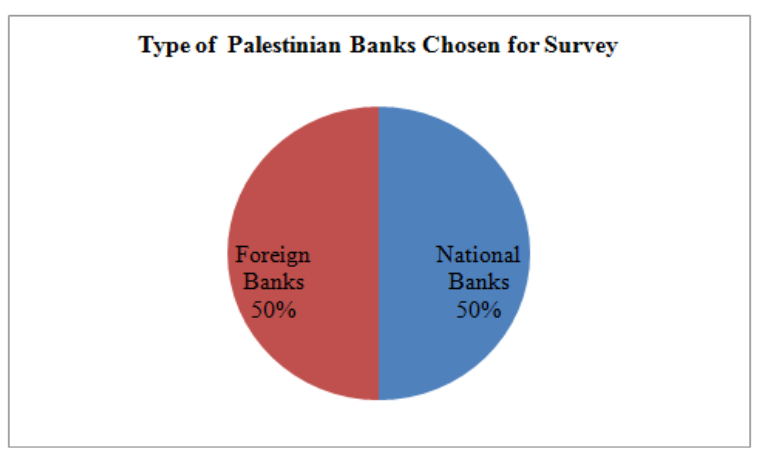

Figure 1. Type of Palestinian Banks Chosen for Survey.

Table 1. Survey Responses for Managerial and Control Issues.

\begin{tabular}{lll}
\hline The managerial supervision and control & Frequency of Agreement & Standard Deviation \\
\hline 1. New Basel 2 has increased management performance in terms of strategy and setting risk limits & $100 \%$ & 4.47 \\
2. Executive management periodically reviews the business strategies and control practices aligned & $90 \%$ & 3.94 \\
with international practices & $70 \%$ & 2.92 \\
3. Power are delegated to develop effective internal control & \\
\hline
\end{tabular}

Table (1) has summarized the impact of internal control on increasing the performance of banks' management. However, the delegation of power was realized still as a challenging issue in Palestinian banks (only 70\% agreed and low deviation between agreement and disagreement).

It can be determined from the figure that banks chosen for survey participation were equally divided into 5 national and 5 foreign banks. The reason behind such segregation was to eliminate the bias and to focus on the collective issues and impacts of internal control and risk management system in banks.

Table 2. Survey Responses for Impact on Risk Identification and Assessment.

\begin{tabular}{lll}
\hline Risk identification and assessment & Frequency of Agreement & Standard Deviation \\
\hline 1. Risk is assessed using the principles of cost and benefit & $100 \%$ & 4.47 \\
2. Difficulty in assessing financial risk due to Israeli and USA currency dependency & $100 \%$ & 4.47 \\
3. Financial risk is the key risk in my bank & $60 \%$ & 2.83 \\
4. Staff have become trained and informed after banking reformation & $70 \%$ & 2.92 \\
5. Basel 2 compliance has reduced uncertainty up to greater extent & $90 \%$ & 3.94 \\
6. Stress testing is used to assess the risk periodically & $100 \%$ & 4.47 \\
\hline
\end{tabular}

Table (2) determines that current risk assessment in Palestine; banks have improved in terms of assessment $(100 \%)$, reducing uncertainty $(90 \%)$ and periodic assessment $(100 \%)$ while foreign currency dependency and staff training is still demanding issues having negative consequences. Financial risk is not identified as key risk by $60 \%$ of respondents.

Table 3. Survey Responses for Impact on Risk Control.

\begin{tabular}{lll}
\hline Control activities and segregation of duties & Frequency of Agreement & Standard Deviation \\
\hline 1. Controls are placed on access to banks' assets & $100 \%$ & 4.47 \\
2. Special limits are set for risk in different categories & $90 \%$ & 3.94 \\
3. Approvals and authorizations are incorporated & $80 \%$ & 3.46 \\
4.Employees are not allowed conflicting functions & $70 \%$ & 3.08 \\
5. Chances of fraud and manipulation have reduced & $100 \%$ & 4.47 \\
6.Errors do occur frequently & $60 \%$ & 2.55 \\
\hline
\end{tabular}

On other hand, Table (3) depicted that internal controls are helping banks in controlling their risks. The cautious issue was the identification that still conflicting functions are influencing banks negatively $(70 \%)$.

Table (4) highlights the deficiencies in the information and communication challenges resulting in difficulty to identify and mitigate risks in timely manner.

Table (5) reported that internal control and risk management have positively affected the banks. However, the focus on autonomy of internal controllers was realized as 
vital challenge $(60 \%)$.

Table 4. Survey Responses for Impact on Communication and Information Sharing.

\begin{tabular}{lll}
\hline Information Systems and Communication & Frequency of Agreement & Standard Deviation \\
\hline 1. Effective channels of communication are used & $60 \%$ & 2.35 \\
2. Flow of data has become horizontally aligned & $83 \%$ & 2.17 \\
3. Latest information and control applications are used & $86 \%$ & 2.61 \\
\hline
\end{tabular}

Table 5. Survey Responses for Impact on Bank's Operations.

\begin{tabular}{lll}
\hline Follow-up operations and corrections of imbalances & $\begin{array}{l}\text { Frequency of } \\
\text { Agreement }\end{array}$ & Standard Deviation \\
\hline $\begin{array}{l}\text { 1. Independent audit system is used for assessing the performance } \\
\text { 2. Autonomy of internal controller and professional capacity of internal controller is given importance }\end{array}$ & $60 \%$ & 2.35 \\
$\begin{array}{l}\text { 3. Basel Committee have confirmed the need to inform the administrative level on a timely manner with } \\
\text { any gaps or problems in the internal control system }\end{array}$ & $100 \%$ & 2.83 \\
$\begin{array}{l}\text { 4. Overall internal control and risk management systems in Palestine have positively impacted the banks } \\
\text { in terms of quantitative as well as qualitative performance }\end{array}$ & $100 \%$ & 4.47 \\
\hline
\end{tabular}

\section{Conclusion}

The findings can be concluded that Palestine's banking sector has improved in current era after implementation of new reforms and laws associated with the internal control and risk management strategies. The different aspects of both the mechanisms have introduced new requirements and instructions on the operation of banking sector. The analysis of the literature revealed that banks still facing issues related with independency of internal control and foreign currency fluctuations due to absence of national currency. However, banks were found active in using the PMA instructions and Basel 2 framework for timely identification of different types of risks. These commitments can be deemed as the reason behind the reduction in financial risk in some of the banks. The systems are helping the banks in limiting their risk limits and assessing these periodically. The cost and benefit principle involving all the individuals from top to bottom levels of management and operational staff in the internal control and risk management has led positive quantitative and quantitative impacts in bank's profit as well as overall performances. However, it would be recommended that banks must consider staff training as a major factor for effective working of both the mechanisms.

\section{References}

[1] Abdelkarim, Naser and Maisa Burbar. How Banks in Palestine Manage Financial Risk? . Jordan : Al-Zaytoonah University, 2007.

[2] Arif, Ahmed and Ahmed Nauman Anees. "Liquidity risk and performance of banking system." Journal of Financial Regulation and Compliance, 20(2) (2012): 182-195.

[3] Bahu, Rana, Eric Melloul and William Walsh. Banking Law Reform in the Palestinian Territories. IPCRI, Law \& Development Program, 1995.

[4] Banking Regulation and Supervision Board. "Regulation on Banks' Internal Control and Risk Management Systems." 2001.
[5] Bryman, Alan and Emma Bell. Business Research Methods. New York: Oxford University Press, 2007.

[6] Cobham, David and Nu'man Kanafani. The Economics of Palestine: Economic Policy and Institutional Reform for a Viable Palestine State. UK: Routledge, 2004.

[7] D. P. Dube, Ved Prakash Gulati. Information System Audit and Assurance. New Dehli : Tata McGraw-Hill Education, 2005 .

[8] Greuning, Hennie van and Sonja Brajovic Bratanovic. Analyzing Banking Risk: A Framework for Assessing Corporate Governance and Risk Management. World Bank Publications, 2009.

[9] Hayali, Ayşe, et al. IMPORTANCE OF INTERNAL CONTROL SYSTEM IN BANKING SECTOR : EVIDENCE FROM TURKEY. Thesis. Turkey: Marmara University, 2012.

[10] IBP USA. Palestine (West Bank and Gaza) Country Study Guide: Strategic Information and Developments. IBP USA: Int'l Business Publications, 2014.

[11] ibrabas. Palestinian Banks and Application of Basel 2 Related to the Internal Control. Israel: Booksie, 2015.

[12] Kapoulas, Alexandros and Miljana Mitic. "Understanding challenges of qualitative research: rhetorical issues and reality traps." Qualitative Market Research: An International Journal, 15(4) (2012): 354-368.

[13] Karyn L. Neuhauser. "Survey research in finance." International Journal of Managerial Finance, 3(1) (2007): 5-10.

[14] PMA. PMA Issues New Instructions to Banks on Stress Testing. 10 November 2014. 13 March 2015 $<$ http://www.pma.ps/Default.aspx?tabid=205\&ArtMID=793\& ArticleID $=614 \&$ language $=$ en-US $>$.

[15] PPA. Banking and Financial Sector. 2015. 13 March 2015 $<$ http://www.pipa.gov.ps/banking.asp>.

[16] Quigley, John B. The Case for Palestine: An International Law Perspective. UK: Duke University Press, 2015.

[17] Sensarma, Rudra and M. Jayadev. "Are bank stocks sensitive to risk management?" The Journal of Risk Finance, 10(1) (2009): 7-22.

[18] Silverburg, Sanford R. Palestine and International Law: Essays on Politics and Economics. UK: McFarland, 2002. 
161 Mohammed Bayyoud and Nermeen Ahmad Sayyad: The Impact of Internal Control and Risk Management on Banks in Palestine

[19] Socol, A. "Internal Banking Control and Audit: A Comparative Approach in the Romanian Banking Sector." Annales Universitatis Apulensis Series Oeconomica, 13(2) (2011): 396-403.
[20] Valdivieso, Rosa. The West Bank and Gaza: Economic Performance, Prospects, and Policies: Achieving Prosperity and Confronting Demographic Challenges. Washington: International Monetary Fund, 2001. 